\title{
Predicting PCB concentrations in cow milk: validation of a fugacity model in high-mountain pasture conditions
}

\author{
Paolo Tremolada ${ }^{\mathrm{a}, *}$, Niccolò Guazzoni ${ }^{\mathrm{a}}$, Marco Parolini ${ }^{\mathrm{a}}$, Bruno Rossaro ${ }^{\mathrm{b}}$, \\ Marta Maria Bignazzi ${ }^{\mathrm{a}}$, Andrea Binelli ${ }^{\mathrm{a}}$ \\ a Department of Biosciences, University of Milan, Via Celoria 26, Milan I-20133, Italy \\ b Department of Food, Environmental and Nutritional Sciences, University of Milan, Via Celoria 2, Milan I-20133, Italy
}

\section{H I G H L I G H T S}

- PCB contamination in vegetation, concentrate, cow milk and faeces are presented.

- PCB contamination in food were used to validate a fugacity model for milk.

- The model was optimized for high-mountain pasture conditions with good results.

\section{A R T I C L E I N F O}

\section{Article history:}

Received 29 November 2013

Received in revised form 11 April 2014

Accepted 11 April 2014

Available online xxxx

Editor: Adrian Covaci

\section{Keywords:}

POP modelling

Fugacity model

Polychlorinated biphenyls (PCBs)

Cow milk

Mountain contamination

\begin{abstract}
A B S T R A C T
A fugacity model reported in the literature was applied to a high-altitude pasture in the Italian Alps. The model takes into account three compartments (digestive tract, blood and fat tissues) in unsteady-state conditions using food as the contamination source. Disregarding biotransformation inside cow tissues, the predicted concentrations of 14 polychlorinated biphenyls (PCBs) in milk were in good agreement with the observed data, especially for congeners known for their resistance to biotransformation (e.g., CB-138 and 153). In contrast, the predicted concentrations were clearly overestimated for congeners with high biotransformation susceptibilities. Therefore data measured in milk and faeces were used to calculate the first-order-biotransformation rate constants in dairy cows. The PCB absorption efficiency observed for pasture conditions was lower than that observed in the cowshed. The final version of the model included biotransformation and observed PCB absorption and was able to predict PCB concentrations in cow milk with mean differences between the predicted and measured data below $\pm 20 \%$ for most congeners.
\end{abstract}

(c) 2014 Elsevier B.V. All rights reserved.

\section{Introduction}

Since 2001, polychlorinated biphenyls (PCBs) have been banned worldwide by the Stockholm Convention. Nonetheless, as a consequence of their extensive use in the past (Breivik et al., 2002), their dispersion by long-range atmospheric transport (Wania and Su, 2004) and their persistence (Borja et al., 2005), PCBs can still be found almost everywhere. Milk and dairy products are important sources of persistent organic pollutants (POPs) to humans (Duàrte-Davidson and Jones, 1994). Knowing vegetation-to-milk transfer rates is important to both evaluate human exposure and to assess pasture food-chain integrity (Fries, 1977; McLachlan et al., 1990). McLachlan (1993)

\footnotetext{
is Capsule. A fugacity model for predicting POP concentrations in milk was applied to field data in a mountain pasture area: the final version of the model provided reliable predictions.

* Corresponding author. Tel.: + 3902 50314715; fax: + 390250314713.

E-mail address: paolo.tremolada@unimi.it (P. Tremolada).
}

studied the mass balance of PCBs in a controlled trial with lactating cows and established that nearly the cow's entire intake of several POPs was through its feed (relative intake $>99 \%$ ), while contamination coming from the air and water was negligible. At least two studies (McLachlan, 1993; Thomas et al., 1999a) have reported absorption efficiencies near $80 \%$ for PCB congeners having $\log K_{\text {ow }}<6.5$ (e.g., penta-chlorinated and less-chlorinated congeners), while absorption efficiencies drop below $20 \%$ for those with $\log K_{\text {ow }}>8$ (CB-209, McLachlan, 1993). Non-absorbed PCBs are eliminated through faeces ( McLachlan, 1993). In accordance with their absorption efficiencies (up to $80 \%$ ), PCBs are rapidly transferred from the gastrointestinal tract to the milk. After a single contaminant input, a milk contamination peak was observed after 2-3 days, while the fat contamination peak was observed much later, indicating preferential transfer to the milk in comparison to fat deposits (Olling et al., 1991; Slob et al., 1995). Bloodstream lipids comprise the main PCB transfer medium in the cow, passing from the digestive tract to other tissues and to the udder glands (Thomas et al., 1999b). Fat tissues have high capacities but slow 
recharge/discharge rates and are able to flatten out the contamination in the milk, acting as additional sources of contamination in the case of decreasing inputs from food (Sweetman et al., 1999). By analysing biotransformation susceptibility, McLachlan (1993) found that the presence of chlorine atoms in para and para' positions is a key parameter in determining the biotransformation and persistence of different congeners. Furthermore, Matthews and Dedrick (1984) demonstrated that the presence of two adjacent hydrogen atoms, especially in the meta- and para-positions, increased PCB biotransformation susceptibility.

Modelling approaches are very useful, not only for prediction but also for understanding and describing the environmental fates of contaminants. Pollutant fate and milk contamination in a particular cow depend on both PCB inputs and the physiological status of the cow. For example, after calving, cows reduce their fat deposits, resulting in an observed weight loss of $3.8 \mathrm{~kg} \mathrm{~d}^{-1}$ (Sweetman et al., 1999). This decrease in fat deposits can increase contaminant flux into the milk, causing milk concentrations to rise up to 4 times the levels determined during periods of maximum weight gain (Sweetman et al., 1999). These variations in cow weight and milk production must be carefully evaluated when a single cow is considered, but, when modelling general milk contamination within a herd, average physiological conditions may be sufficient. In dairy farms, milk is harvested in common bulk tanks, and this procedure generally averages the contamination differences among individuals under different physiological conditions. Generally, milk cows have lactating cycles that shift in time, enabling them to distribute calving events over the entire year. Therefore, milk contamination of a herd will depend more on input fluxes than the physiological status of an individual cow. This assumption enables tremendous simplification of the model and permits the prediction of milk concentrations from food contamination levels and the average characteristics of the herd (e.g., average milk production and milk lipid content).

In 1994, a fugacity model was proposed to describe the vegetation-to-milk transfer of persistent lipophilic compounds in dairy cows (McLachlan, 1994) and was validated using a backgroundcontaminated diet under controlled conditions. More complex pharmacokinetic models have also been proposed (Derks et al., 1994), but, despite their complexity, their predictions did not provide any better fits with the measured concentrations (Sweetman et al., 1999).

Fugacity models are based on the fugacity concept (Mackay, 2001), where the fugacity of a compound in a specific environmental compartment (e.g., water, air, etc.) is directly related to concentration by means of the fugacity capacity of the compartment. Fugacity models

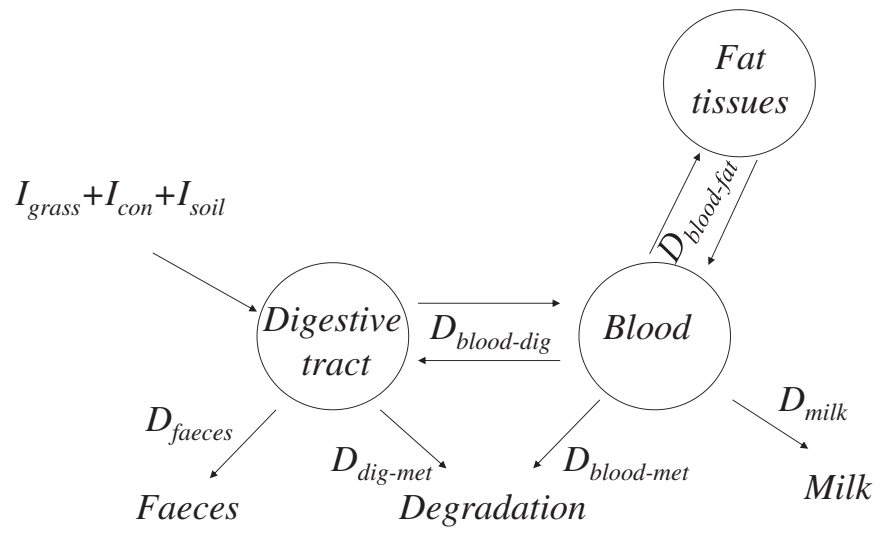

Fig. 1. Scheme of the fugacity model derived from McLachlan (1994). Digestive tract, blood and fat tissues are the three considered cow compartments; $I_{\text {grass }}, I_{\text {con }}$ and $I_{\text {soil }}$ are the input fluxes of PCBs from grass vegetation, concentrates and accidentally ingested soil, respectively, and the $D$-values are flux parameters of the following different types: exchange $D$-values ( $D_{\text {blood-dig }}$ and $D_{\text {blood-fat }}$ ), reaction $D$-values ( $D_{\text {dig-met }}$ and $D_{\text {blood-met }}$ ) and advection $D$-values ( $D_{\text {faeces }}$ and $\left.D_{\text {milk }}\right)$. are suitable for non-ionised chemicals that have measurable vapour pressures.

The goal of the present work is to validate a fugacity model proposed by McLachlan (1994) by applying it to a herd under free pasture conditions, in which a number of cows are kept outdoors in a high-altitude pasture in the Alps, feeding almost exclusively on natural herbaceous vegetation. In an unsteady-state form, McLachlan's model appears to be sufficiently realistic and simple for easy applicability. More detailed aims of this work are as follows: a) validation of a fugacity model, as applied at the herd level in a mountain pasture (uncontrolled feeding conditions); b) prediction of the time-trend of milk contamination during the pasture season; and c) analysis of transfer rates and absorption efficiencies under high-mountain pasture conditions. Toward these ends, PCB levels in the grass, concentrate, soil, milk and faeces were measured in a mountain area in the Italian Alps at 1900 $\mathrm{m}$ a.s.l. during the pasture season (from June to September). Concentrations of different PCB congeners in the milk and faeces were related to input fluxes measured in the grass, concentrate and soil.

\section{Materials and methods}

\subsection{Study area and sampling}

The study area (Andossi plateau) is a grassland plateau in the Central Italian Alps (Fig. S1) that spans approximately $5 \mathrm{~km}^{2}$ along an altitudinal gradient from 1900 to $2200 \mathrm{~m}$ a.s.l. This area has been used as pasture for a long time and is currently grazed by milking cows. The experimental area is a relatively remote area at high altitude in the Alps, without any direct contamination sources. The origin of the contamination is the regional atmospheric transport from morecontaminated surrounding areas (highly industrialised plain areas below Alps). A sampling campaign was performed from May until November 2011. The sampling dates were as follows: May 20th (T1, before pasture season); June 1st, 12th and 22nd (T2, T3 and T4, respectively); July 3rd and 15th (T5 and T6, respectively); August 5th and 17th (T7 and T8, respectively); September 7th and 15th (T9 and T10, respectively); and November 14th (T11, after the pasture season). Concentrate (given as supplementary feed), milk and faeces were collected during the afternoon milking, while herbaceous vegetation and soil samples were taken during early afternoon from different plateau sites. Milk samples were taken before pasture season (T1), when the cows were kept indoors at low altitude, and throughout the pasture season (T2, T4, T5, T6, T7, T8, T9 and T10) on the Andossi plateau. For each date, an integrated milk sample was collected from the common milking tank to avoid individual inter-variability (Sweetman et al., 1999). Seven faeces samples were taken on T4, T5, T6, T7, T8, T9 and T10. For each sampling, three sub-samples were taken randomly from three different cows, selecting from faeces that was freshly produced during milking operations (by the same cows that were sampled for milk). The three sub-samples of each sampling came from three different cows, but the differently dated faeces samples were not necessarily from the same cow. Each faeces subsample was taken at two-thirds of the faeces height to avoid the surface and possible contamination from the soil.

Only three concentrate samples were taken on T6, T7 and T9 because these concentrate samples were assessed as relatively homogeneous, coming from the same commercial stock. Integrated grass samples were taken on T4, T5, T6, T7, T8, T9 and T10 from three sub-areas in a flat site where the cows feed abundantly due to the grass type and amount. Additionally, more vegetation samples were taken with the same modalities in two nearby sites at the same altitude but with opposite exposure (north-facing and south-facing slopes) on T1, T2, T3, T4, T5, T6 and T11. The North and South slopes were determined by small hills (approximately $100 \mathrm{~m}$ in height and $200 \mathrm{~m}$ in width) that compose part of the plateau landscape. North and South grass samples were taken to verify the spatial variability of the contamination 
in the pasture area and the existence of a North/South enrichment factor (in vegetation), as proposed by Tato et al. (2011).

\subsection{Analytical procedures}

In each matrix, 14 PCB congeners $(18,31+28,52,44,101,149,118$, $153,138,180,170,194$ and 209) were analysed, according to their presence in the Italian environment and their degrees of chlorination (from tri- to deca-chlorination classes). Frozen samples were lyophilised, extracted using a Soxhlet apparatus, purified using concentrated sulphuric acid and a Silica-Florisil column and analysed by GC-MS/MS. A detailed description of the analytical procedures and statistical analyses is reported in the Supplementary Information (SI) section.

\subsection{The model}

The dynamic multicompartmental model used to describe contamination transfer from food to milk was first developed by McLachlan (1994). The cow was divided into the following three compartments: the lumen of the digestive tract, blood and fat (Fig. 1). For the digestive tract compartment, contaminant uptake via feed and via diffusive transport from the blood compartment were considered, while the contaminant loss processes that were considered were diffusive transport into the blood compartment, contaminant transformation in the digestive tract, and excretion via the faeces. For the blood compartment, contaminant uptake via diffusive transports from the digestive tract and the fat compartments were considered, while the contaminant loss processes were the same reverse diffusive transports into the digestive tract and fat compartments, contaminant transformation in the blood and excretion via the milk. For the fat compartment, contaminant uptake via diffusive transport from the blood compartment was considered, while the contaminant loss process was the same reverse diffusive transport into the blood. In pasture conditions, contaminant uptake via feed is derived mainly from ingested grass, secondly from concentrate given as supplementary feed and finally from accidentally ingested soil during grazing. Following McLachlan's approach (1994), three mass-balance differential equations are able to describe the fate of PCBs in cows under unsteady-state conditions (Eqs. (1)-(3)).

$\frac{d f_{\text {dig }}}{\mathrm{dt}}=\left(D_{\text {grass }} f_{\text {grass }}+D_{\text {conc }} f_{\text {conc }}+D_{\text {soil }} f_{\text {soil }}+D_{\text {blood-dig }} f_{\text {blood }}-\left(D_{\text {faece }}+D_{\text {dig-met }}\right) f_{\text {dig }}\right) / V_{\text {dig }} Z_{\text {dig }}$

$$
\begin{aligned}
\frac{d f_{\text {blood }}}{\mathrm{dt}} & =\left(D_{\text {blood-dig }} f_{\text {dig }}+D_{\text {blood-fat }} f_{\text {fat }}-\left(D_{\text {blood-dig }}+D_{\text {blood-fat }}+D_{\text {milk }}+D_{\text {blood-met }}\right) f_{\text {blood }}\right) \\
& / V_{\text {blood }} Z_{\text {blood }}
\end{aligned}
$$

$\frac{d f_{\text {fat }}}{\mathrm{dt}}=\left(D_{\text {blood-fat }} f_{\text {blood }}-D_{\text {blood-fat }} f_{\text {fat }}\right) / V_{\text {fat }} Z_{\text {fat }}$

Symbols used in Eqs. (1)-(3) are defined in Tables S1 and S2. To simplify the equations and calculations and taking into account that PCBs are highly lipophylic compounds, cow compartments and advection media (vegetation, concentrate, faeces and milk, excluding soil) in Eqs. (1)-(3) are reduced to their lipid fractions only, based on the assumption that PCBs distribute almost exclusively to lipid fractions. This is justified by the literature and, for the cow compartments, by the findings of Thomas et al. (1999b), who demonstrated near equilibrium conditions on a lipid base among the cow compartments (excluding the liver). For all compartments and especially for vegetation and concentrates, this assumption may be an oversimplification because additional molecular structures can be important for the storage of lipophylic contaminants (Barber et al., 2004). However, we believe that, for the goals of this paper, simplification by calculating the fugacity capacity based on the lipid content is acceptable. In the case of the soil, the organic carbon fraction was considered because this fraction is currently used to predict the accumulation of persistent lipophylic compounds in the soil (e.g., Daly et al., 2007).

In Eqs. (1)-(3), $f_{\text {dig }}, f_{\text {blood }}$ and $f_{\text {fat }}$ ( $f$ expressed in Pa) are the fugacities of the compound in the digestive tract, bloodstream and fat, respectively, taking into account that the digestive tract and blood compartments are represented by their lipid fractions. These three variables are the unknown variables in the three equation system. In Eq. (1), the terms $f_{\text {grass }}, f_{\text {conc }}$ and $f_{\text {soil }}$ are the fugacities of PCBs in the grass, concentrate and soil, respectively, taking into account that grass and concentrate compartments are represented by their lipid fractions and that the soil compartment is represented by its organic carbon fraction. The variables $f_{\text {grass }}$ and $f_{\text {conc }}$ were calculated as the ratios between the concentrations of each compound in terms of its lipid base ( $\mathrm{mol} \mathrm{m}^{-3}$ of lipid) and the fugacity capacity of octanol $\left(Z_{\text {octanol }}\right.$ in $\mathrm{mol} \mathrm{m}^{-3} \mathrm{~Pa}^{-1}$; Table S1). The variable $f_{\text {soil }}$ was calculated as the ratio between the concentration of each compound in terms of its organic carbon base $\left(\mathrm{mol} \mathrm{m}^{-3}\right.$ of organic carbon) and the fugacity capacity of organic carbon of soil $\left(Z_{\mathrm{OC}-\text { soil }}\right.$ in mol m${ }^{-3} \mathrm{~Pa}^{-1}$; Table S1). In Eqs. (1)-(3), the different $D$-values $\left(D_{\mathrm{i}}\right.$ in mol d $\left.{ }^{-1} \mathrm{~Pa}^{-1}\right)$ pertain to the following phenomena: advection fluxes ( $D_{\text {grass }}, D_{\text {conc }}, D_{\text {soil }}, D_{\text {faeces }}$ and $D_{\text {milk }}$ ), biotransformation processes ( $D_{\text {dig-met }}$ and $D_{\text {blood-met }}$ ) and diffusive transports ( $D_{\text {blood-dig }}$ and $\left.D_{\text {blood-fat }}\right)$. These $D$-values are defined in Table $\mathrm{S} 1$. The variables $V_{\text {dig, }}, V_{\text {blood }}$ and $V_{\text {fat }}$ in Eqs. (1)-(3) are the compartment volumes $\left(V_{i}\right.$ in $\mathrm{m}^{3}$ ) of the digestive tract, bloodstream and fat, respectively, taking into account that the digestive tract and blood compartments are represented by their lipid fractions, and therefore, their volumes are considered equal to their lipid contents (Table S2). The variables $Z_{\mathrm{dig}}, Z_{\mathrm{blood}}$ and $Z_{\mathrm{fat}}$ in Eqs. (1)-(3) are the capacities of the digestive tract, bloodstream and fat compartment, respectively $\left(Z_{i}\right.$, units of mol m$\left.{ }^{-3} \mathrm{~Pa}^{-1}\right)$. Taking into account that the digestive tract and blood compartments are represented by their lipid fractions and that fat refers to cow lipids, $Z_{\mathrm{dig}}, Z_{\mathrm{blood}}$ and $Z_{\mathrm{fat}}$ are considered equal to $Z_{\text {octanol }}$ (Table S1). The equation system (1-3) was numerically solved using the 'ode' function of the deSolve package of $\mathrm{R}$ free software (R Core Team, 2013).

\section{Results and discussion}

\subsection{PCBs in vegetation and concentrates}

The complete dataset of PCB concentrations in the grass and concentrate samples from the Andossi plateau is reported in Table S3. Mean concentration of the PCB sums ( $\Sigma$ PCBs) detected in vegetation was $0.85 \pm 0.64 \mathrm{ng} \mathrm{g}^{-1}$ dry weight (range $0.25-2.51 \mathrm{ng} \mathrm{g}^{-1}$ d.w.), which was slightly lower than that measured in the same matrix and area in 2008 (1.1 $\pm 0.50 \mathrm{ng} \mathrm{g}^{-1}$ d.w.; Tato et al., 2011) and that measured by Nizzetto et al. (2008) in 2005.

PCB contamination in the concentrates (mean of $0.18 \pm$ 0.029 ng $\Sigma$ PCBs g ${ }^{-1}$ d.w, range $0.15-0.20$ ng g $^{-1}$ d.w., Table S3) was lower than that determined for grass. The low measured variability in PCB concentrations in the concentrates (variation coefficient of $16 \%$ ) confirms the hypothesis of a homogeneous contamination level of this food. In 2008, concentrate samples were slightly less polluted $\left(0.10 \pm 0.060 \mathrm{ng} \Sigma \mathrm{PCBs} \mathrm{g}^{-1} \mathrm{~d} . \mathrm{w}\right)$, but this finding can be explained by differences in commercial stocks. The relative abundance of the congeners in the concentrate differed from the contamination fingerprints found in the vegetation (Fig. S2) due to the different origins of the raw materials.

Whereas PCB levels in concentrate were nearly constant during pasture season (indicating well mixed and homogeneous food), the concentrations in the grass were quite variable for this small and relatively homogeneous area (Table S3). This relatively high variability on the local scale is consistent with results reported in the literature for vegetation (Tato et al., 2011) and soil (Guazzoni et al., 2011). 
This variability requires interpretation because grass is the main PCB contamination source for dairy cows ( $88 \%$ of the total contamination). The integrated and complex compositions of vegetation samples, taken without selection by cutting all of the above-ground herbaceous vegetation, resulted in an averaging, at least in part, of accumulation differences due to different species and vegetation stages (Böhme et al., 1999). Additionally, to reduce this possible variability source, the concentration data were analysed after lipid normalisation. The lipid content of each sample ranged between 0.010 and $0.022 \mathrm{~g}$ lipid $\mathrm{g}^{-1}$ d.w., with a mean lipid content of $0.015 \pm 0.0034 \mathrm{~g}$ lipid $\mathrm{g}^{-1}$ d.w. The South and North sites revealed significant differences in mean lipid content in the

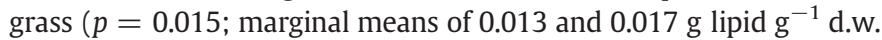
for the North and South sites, respectively, calculated using the General Linear Model). This difference, which derives from the different pedoclimatic conditions of the two sites, affects PCB concentration differences between the North and South sites when dry-weightnormalised concentrations are normalised to the lipid base. Lipid normalisation does not result in complete normalisation of the concentrations in the grass, because other, non-lipid molecular structures can also be important in the storage of lipophylic contaminants in plants (Böhme et al., 1999; Barber et al., 2004). However, lipid normalisation can better approach the actual accumulation capacity of vegetation than dry-weight normalisation. A General Linear Model of lipidnormalised concentrations was used to analyse both the spatial variability among sites at the same altitude but with different exposure (North and South) and the time variability during the vegetative season (from May to November). Both exposure and date factors were significant for many congeners and for $\Sigma$ PCBs $(p=0.033$ and $p=0.009$ for the exposure and date factors, respectively). The exposure effect leads to a North/South enrichment factor of the lipid-normalised concentrations of 1.5 for $\mathrm{EPCBs}$ (Fig. S3), confirming the findings of Tato et al. (2011). The seasonal trend in vegetation was evaluated only from May to November (the snow-free season at that altitude). Fig. S4 shows low PCB concentrations in middle summer (July), a concentration peak in June and relatively high levels at the beginning (May) and end (November) of the growing season. Maximum differences of marginal mean concentrations in vegetation were approximately one order of magnitude, suggesting the presence of a relevant seasonal variability, as described by Tato et al. (2011). Nizzetto et al. (2008) reported a seasonal pattern in vegetation that was mainly driven by temperature. We think the observed seasonal trend in vegetation in the present study was more likely due to the synergy of the following factors: temperatures that drive concentrations in air and accumulation potentials in soil and plants, rain/snow events that enhance deposition phenomena (Tremolada et al., 2008), and volatilisation fluxes from soil that are able to enrich the soil-air boundary level that is directly in contact with herbaceous vegetation (Tato et al., 2011). Analysis of the data collected in this work does not enable quantification of the relative contributions of the aforementioned factors, but the observed seasonal variability in vegetation must be taken into account to assess contamination inputs to dairy cows. In contrast, spatial variability is not considered because the grazing activity effectively averages the PCB contamination levels coming from different sites (e.g., NorthSouth differences). Additionally, cows preferentially feed at flat sites, where vegetation grows abundantly and contaminant levels are intermediate with respect to North and South exposure (Tato et al., 2011).

\section{2. $P C B$ in milk and faeces}

The complete dataset of PCB concentrations in milk and faeces is reported in Table S4. .PCBs in milk ranged between 0.75 and $1.33 \mathrm{ng} \mathrm{g}^{-1}$ d.w., with a mean concentration of $1.16 \pm 0.18 \mathrm{ng} \mathrm{g}^{-1} \mathrm{~d}$.w. These levels are lightly lower than concentrations measured in 2008 in the same area $(1.82 \pm$ $0.52 \mathrm{ng} \mathrm{g}^{-1}$ d.w., Tato et al., 2011). Concentrations measured in milk in 2008 and 2011 on the plateau agree with the mean levels measured in other areas of Italy (Esposito et al., 2009) or in other European countries
(Focant et al., 2003; Petro et al., 2010). In analysing single congener concentrations in our milk samples, only CB-101 in the T2 sample was identified as an evident outlier by box-plot analysis; therefore, this datum was not considered further. In general, CB-101 concentrations were quite high in comparison to $\mathrm{CB}-118$ ones. In faeces the $\mathrm{CB}-101 / \mathrm{CB}-118$ ratio was very similar to that in vegetation (Fig. S2), while this ratio in milk was lower. Thomas et al. (1999a, 1999b) found a much lower proportion of congener 101 in comparison to 118 in the UK milk, mainly because CB-101 was largely metabolised. Our observed decrease in milk of CB-101 was not so evident. Co-elution of CB-101 with CB-99 was analytically excluded; therefore we must conclude that CB-101 biotransformation observed in our pasture conditions was not evident as in other studies (Thomas et al., 1999a, 1999b). However, other studies reported relatively high proportions of CB-101 in milk: Rossi et al. (2010) reported relative abundant values of $11 \%$ and $23 \%$ for $C B-101$ and CB-118, respectively, and Luzardo et al. (2012) reported an even higher abundance of CB-101 than CB-118 in Canary Islands' milk.

The mean $\Sigma$ PCB concentration in the faeces was $1.05 \pm 0.60 \mathrm{ng}$ $\mathrm{g}^{-1} \mathrm{~d}$.w., ranging between 0.37 and $2.10 \mathrm{ng} \mathrm{g}^{-1} \mathrm{~d}$.w. (Table S4). The mean dry-weight-normalised concentration in the faeces was very similar to that in the milk, but the former's variability was three times higher. Two reasons may account for this result. First, the faeces samples integrate the contribution of few specimens (typically three), while the milk samples are much more representative of the herd (sampling from the common tank where milk is mixed). Secondly, faeces pollution depends more on a single feeding event, while milk contamination averages the loads throughout a longer period (Rossi et al., 2010). Congener compositions of the milk and faeces (Fig. S2) are different from each other as well as in comparison to vegetation compositions. Congener-specific absorption and metabolism are able to modify the congener profiles in milk and faeces relative to that in the feed (McLachlan, 1993; Thomas et al., 1999a, 1999b; Rychen et al., 2008). Congeners that are more easily metabolised in bovines (e.g., congener 52, 44, 149, Thomas et al., 1999b) are mostly depleted in milk rather than in faeces (biotransformation within the cow), while the less-easily absorbed congeners (e.g., congeners having a $\log K_{\text {ow }}>6.5$, McLachlan, 1993) are more abundant in the faeces than in the milk.

\subsection{Input-output mass balance}

Carry-over rates (CORs), based on the balance between input and output fluxes near to steady-state conditions are able to summarise distribution processes, mainly absorption efficiencies and biotransformation, occurring within the cow before milk excretion (McLachlan, 1993; Costera et al., 2006; Kierkegaard et al., 2009; Thomas et al., 1999a). Soil contamination must be considered as a possible source of PCBs because, while grazing, bovines can ingest $1 \%$ to $10 \%$ soil, and this contribution to pollutant uptake may be relevant (Mamontova et al., 2007). On the contrary, other authors emphasised that soil uptake is often overestimated (Fries et al., 1982; Fries, 1996). Dutch authorities estimate an average soil ingestion for grazing milk cows of $0.225 \mathrm{~kg} \mathrm{~d}^{-1}$ (McLachlan, 1997). However, considering the low productivity of high mountain pastures, we decided for a mean accidental soil ingestion of $5 \%$ of the dry amount of the ingested grass. An adult Brown Swiss breed cow (670 kg body weight) eats from 12 to $15 \mathrm{~kg} \mathrm{d.w}$. day ${ }^{-1}$ of grass (Bovolenta et al., 2002). Therefore, the average ingested value of $13.5 \mathrm{~kg}$ d.w. day ${ }^{-1}$ of grass is representative of daily grass intake. Bovolenta et al.'s data refer to a pasture area in the Italian Alps at $2000 \mathrm{~m}$ a.s.l., which is comparable to our experimental area. Considering a mean accidental soil ingestion of $5 \%$ in weight, we obtained a soil flux of $0.675 \mathrm{~kg}$ d.w. day ${ }^{-1}$ for each cow. Multiplying this flux by the mean PCB concentration in the soil $\left(1.8 \pm 0.66 \mathrm{ng} \Sigma \mathrm{PCBs} \mathrm{g}^{-1} \mathrm{~d}\right.$.w. in the superficial layer of these soils, $\mathrm{P}$. Tremolada, personal communication), we obtain a daily PCB flux of $1.22 \mu \mathrm{g} \Sigma \mathrm{PCBs} \mathrm{day}^{-1}$. For grass, considering an average ingested value of $13.5 \mathrm{~kg} \mathrm{d.w.} \mathrm{day}{ }^{-1}$ of grass and the mean $\mathrm{PCB}$ concentration in grass 
Table 1

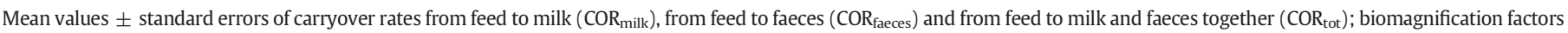

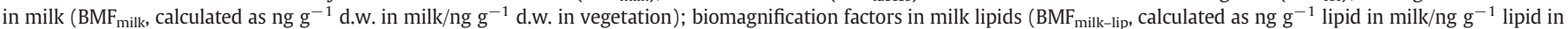

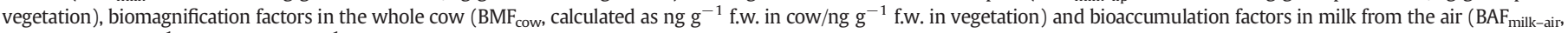

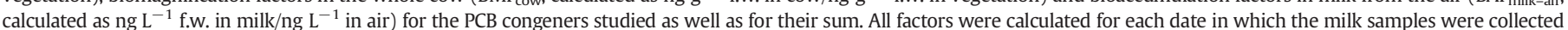
(over the entire pasture season).

\begin{tabular}{|c|c|c|c|c|c|c|c|}
\hline PCB congener & $\mathrm{COR}_{\text {milk }}$ & $\mathrm{COR}_{\text {faeces }}$ & $\mathrm{COR}_{\text {tot }}$ & $\mathrm{BMF}_{\text {milk }}$ dry $\mathrm{W} /$ dry $\mathrm{W}$ & $\mathrm{BMF}_{\text {milk-lip }}$ lipid $\mathrm{W} /$ lipid $\mathrm{W}$ & $\mathrm{BMF}_{\text {cow }}$ fresh $\mathrm{W} /$ fresh $\mathrm{W}$ & $\mathrm{BAF}_{\text {milk-air }}$ fresh V/fresh V \\
\hline 18 & 0.10 & - & - & 0.65 & 0.025 & 0.70 & $5.8 \mathrm{E}+05 \pm 7.1 \mathrm{E}+04$ \\
\hline $31+28$ & $0.11 \pm 0.021$ & $0.39 \pm 0.08$ & $0.50 \pm 0.06$ & $0.69 \pm 0.14$ & $0.032 \pm 0.001$ & $0.69 \pm 0.21$ & $3.6 \mathrm{E}+05 \pm 8.0 \mathrm{E}+04$ \\
\hline 52 & $0.12 \pm 0.033$ & $0.35 \pm 0.05$ & $0.49 \pm 0.07$ & $0.73 \pm 0.30$ & $0.029 \pm 0.009$ & $0.82 \pm 0.40$ & $7.1 \mathrm{E}+05 \pm 4.5 \mathrm{E}+04$ \\
\hline 44 & $0.12 \pm 0.036$ & - & - & $0.78 \pm 0.24$ & $0.029 \pm 0.007$ & $0.92 \pm 0.33$ & $6.1 \mathrm{E}+05 \pm 7.9 \mathrm{E}+04$ \\
\hline 101 & $0.30 \pm 0.075$ & $1.08 \pm 0.39$ & $1.42 \pm 0.44$ & $2.15 \pm 0.58$ & $0.090 \pm 0.025$ & $2.84 \pm 0.83$ & $2.6 \mathrm{E}+06 \pm 7.7 \mathrm{E}+05$ \\
\hline 149 & $0.14 \pm 0.023$ & $0.56 \pm 0.20$ & $0.70 \pm 0.22$ & $1.00 \pm 0.18$ & $0.045 \pm 0.012$ & $1.35 \pm 0.34$ & $3.4 \mathrm{E}+06 \pm 3.6 \mathrm{E}+05$ \\
\hline 118 & $0.44 \pm 0.084$ & $0.64 \pm 0.21$ & $1.10 \pm 0.29$ & $3.36 \pm 0.75$ & $0.143 \pm 0.036$ & $4.46 \pm 1.25$ & $2.1 \mathrm{E}+07 \pm 5.6 \mathrm{E}+06$ \\
\hline 153 & $0.39 \pm 0.072$ & $0.68 \pm 0.25$ & $1.10 \pm 0.31$ & $3.02 \pm 0.67$ & $0.127 \pm 0.029$ & $4.03 \pm 1.05$ & $1.9 \mathrm{E}+07 \pm 5.6 \mathrm{E}+06$ \\
\hline 138 & $0.37 \pm 0.078$ & $0.58 \pm 0.21$ & $0.99 \pm 0.29$ & $2.96 \pm 0.78$ & $0.123 \pm 0.033$ & $4.02 \pm 1.22$ & $1.6 \mathrm{E}+07 \pm 1.1 \mathrm{E}+06$ \\
\hline 180 & $0.23 \pm 0.047$ & $0.55 \pm 0.25$ & $0.79 \pm 0.30$ & $1.87 \pm 0.51$ & $0.087 \pm 0.032$ & $2.52 \pm 0.93$ & $2.1 \mathrm{E}+07 \pm 7.4 \mathrm{E}+06$ \\
\hline 170 & $0.21 \pm 0.035$ & $0.35 \pm 0.07$ & $0.60 \pm 0.05$ & $1.76 \pm 0.32$ & $0.077 \pm 0.017$ & $2.18 \pm 0.41$ & - \\
\hline 194 & - & - & - & - & - & - & - \\
\hline 209 & - & - & - & - & - & - & - \\
\hline$\sum \mathrm{PCBS}$ & $0.28 \pm 0.053$ & $0.62 \pm 0.23$ & $0.93 \pm 0.27$ & $2.15 \pm 0.45$ & $0.094 \pm 0.025$ & $2.91 \pm 0.79$ & $4.9 \mathrm{E}+06 \pm 6.5 \mathrm{E}+05$ \\
\hline
\end{tabular}

(Table S3), we obtained a PCB daily flux of $11.5 \mu \mathrm{g} \Sigma \mathrm{PCBs}$ day ${ }^{-1}$. Because concentrates were given to cows as supplementary feed during milking $\left(2 \mathrm{~kg} \mathrm{day}^{-1}\right.$ ), the PCB daily flux was $0.36 \mu \mathrm{g} \mathrm{SPCBs}$ day $^{-1}$. Considering the overall daily intake $\left(13.08 \mu \mathrm{g} \Sigma \mathrm{PCB}\right.$ day $\left.{ }^{-1}\right)$, the relative contribution of the vegetation, soil and concentrate was $88 \%, 9.3 \%$ and $2.7 \%$, respectively.

Output mass fluxes via milk were also evaluated, taking into account the average milk production of the bovines at pasture (16.3 L f.w. day ${ }^{-1} \operatorname{cow}^{-1}$, weighted mean of data shown in Fig. S1), the mean dry fraction of the milk samples $(0.135 \mathrm{~g}$ d.w./g f.w.,) and an approximate milk density of $1 \mathrm{~kg} \mathrm{dm}^{-3}$. Faeces' mass fluxes were also evaluated considering that, on average, $31.5 \%$ of ingested dry grass is normally eliminated as faeces (Gibb et al., 1992). Thereafter, we obtained output mass fluxes of 2.2 and $4.25 \mathrm{~kg}$ d.w. day ${ }^{-1}$ for milk and faeces, respectively. We calculated the COR for each considered congener as the ratio between PCB output and input fluxes (Table 1). For each analysed congener, Table 1 reports a mean COR value calculated from the COR data obtained for each sampling date, for which both the vegetation and milk concentrations were measured above the limit of quantification. CORs calculated in this study were similar to those obtained in 2008 for the same area, but they were generally lower than those reported in specific mass balance experiments under controlled conditions (McLachlan, 1993; Costera et al., 2006; Kierkegaard et al., 2009), most likely because high-altitude pasture conditions are substantially different from stable conditions (Bovolenta et al., 2002). For example, PCB absorption efficiencies can be lower for cows in pasture conditions because of the different composition of their feed (mainly high-altitude pasture vegetation with low nutritive quality, Andrighetto et al., 1993). The variable $\operatorname{COR}_{\text {tot }}$ is the sum of $\mathrm{COR}_{\text {milk }}$ and $\mathrm{COR}_{\text {faeces }}$, and, for undegradable congeners and supposing conditions near steady-state, it should be close to 1 . This condition was actually observed for congeners 118,153 , and 138 (Table 1 ). However, congeners that are known to be easily degradable $(31+28,52$ and 149) showed low $\mathrm{COR}_{\text {tot }}$ values, as expected. Differences between the calculated $\mathrm{COR}_{\text {tot }}$ values and the unit 1 represent measures of the intensities of biotransformation processes, at least for lowchlorinated congeners, for which a steady-state condition can be supposed. For highly chlorinated congeners, due to the longer time necessary to reach the steady state, the differences between the calculated $\mathrm{COR}_{\text {tot }}$ values and the unit 1 cannot be univocally interpreted as depending on biotransformation. These different interpretations will be discussed later, based on the model predictions.

Moreover, using the ratio between the concentrations in milk and that in vegetation, different biomagnification factors were calculated (BMFs,
Table 1). The lipid-based PCB concentration in milk is a good indicator of the lipid-based PCB concentration in the whole animal, with the exception of the liver (Thomas et al., 1999b). Thus, a BMF cow $_{\text {value was derived }}$ using the lipid fraction of the whole cow ( $0.15 \mathrm{~g}$ lipid/g f.w., Gibb et al., 1992, as reported in Table S2). Additionally, bioaccumulation factors were calculated from air $\left(\mathrm{BAF}_{\text {milk-air }}\right)$, based on concentration data in air measured in the same area and time by passive-air-samplers (P. Tremolada, personal communication). BMF values, determined on a dry-weight basis between the milk and vegetation, and BMF values, determined on a fresh-weight basis between the cow and vegetation, were generally higher than 1 for most congeners, with maximum values of 3-4 for congeners 118,153 and 138 , according to Thomas et al. (1999a). In contrast, BMFs normalised to lipids (0.094 for the $\Sigma$ PCBs) give a completely different picture, indicating that bovines dilute PCBs, derived from vegetation, into a large volume of lipids, which are metabolically produced for lactation and storage purposes. Therefore, PCBs were much more concentrated in vegetation lipids compared to bovine lipids. Vegetation-cow equilibrium is not reached because cows continuously produce lipids and excrete them with their associated lipophilic contaminants throughout milk production, avoiding both gastrointestinal magnification (Gobas et al., 1993) and lipid-based equilibrium. In the present study, the BAFs calculated from air to cow milk showed obvious high values, in accordance with the lipophilicity of these compounds.

\subsection{Modelling elaboration}

A more detailed description of the fate of pollutants in bovines is provided by applying the unsteady-state fugacity model proposed by McLachlan (1994). Physical-chemical properties of the PCB congeners considered (Table S5) and the cow parameters reported in Table S2 were used to solve Eqs. ((1)-(3)) and to calculate the unknown fugacities in the lipids of the three cow compartments (digestive tract, blood and fat) as a function of time (with a resolution of 1 day). Volumes $\left(V_{i}\right)$ and fluxes $\left(G_{i}\right)$ listed in Table S2 were specifically based on the characteristics of cows that were present in the experimental area, while transfer parameters $\left(Q_{i}\right)$ are those proposed by McLachlan (1994). Biotransformation rate constants $\left(k_{i \text {-met }}\right)$ were initially set to 0 because of the lack of quantitative data. The model was solved for a time period corresponding to the 2011 pasture season (from June 1st to September 15th), using time-specific contamination data in grass corresponding to our nine sampling dates from T2 (June 1st) to T10 (September 15th). However, contamination coming from concentrate and soil was considered constant and was evaluated via mean concentrations in these matrices. Soil and concentrate were sampled more 
$\mathrm{a}$

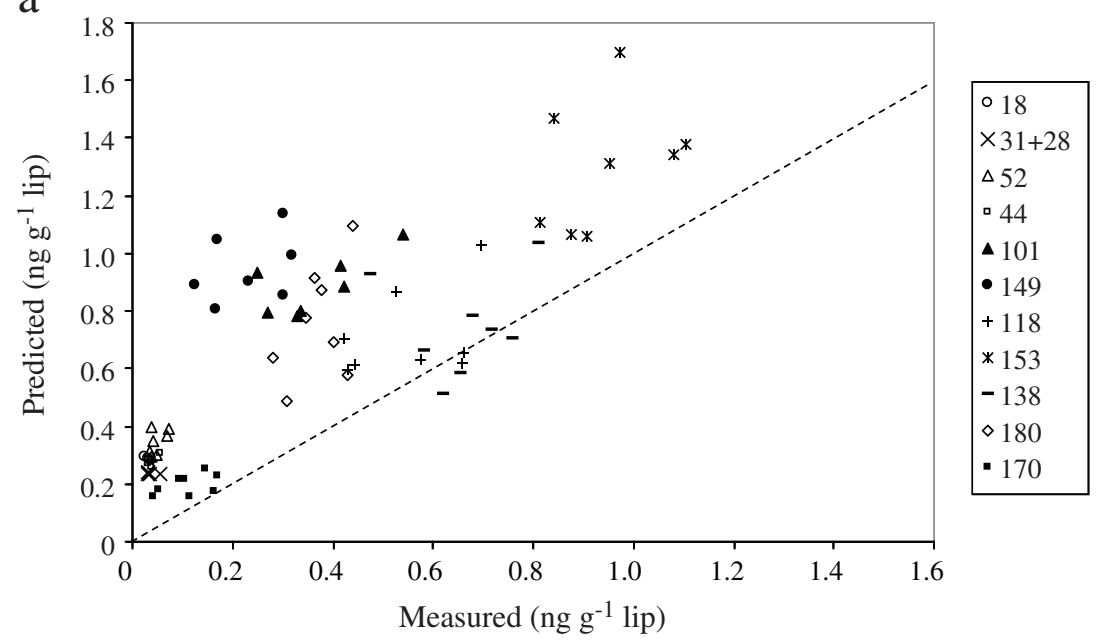

b
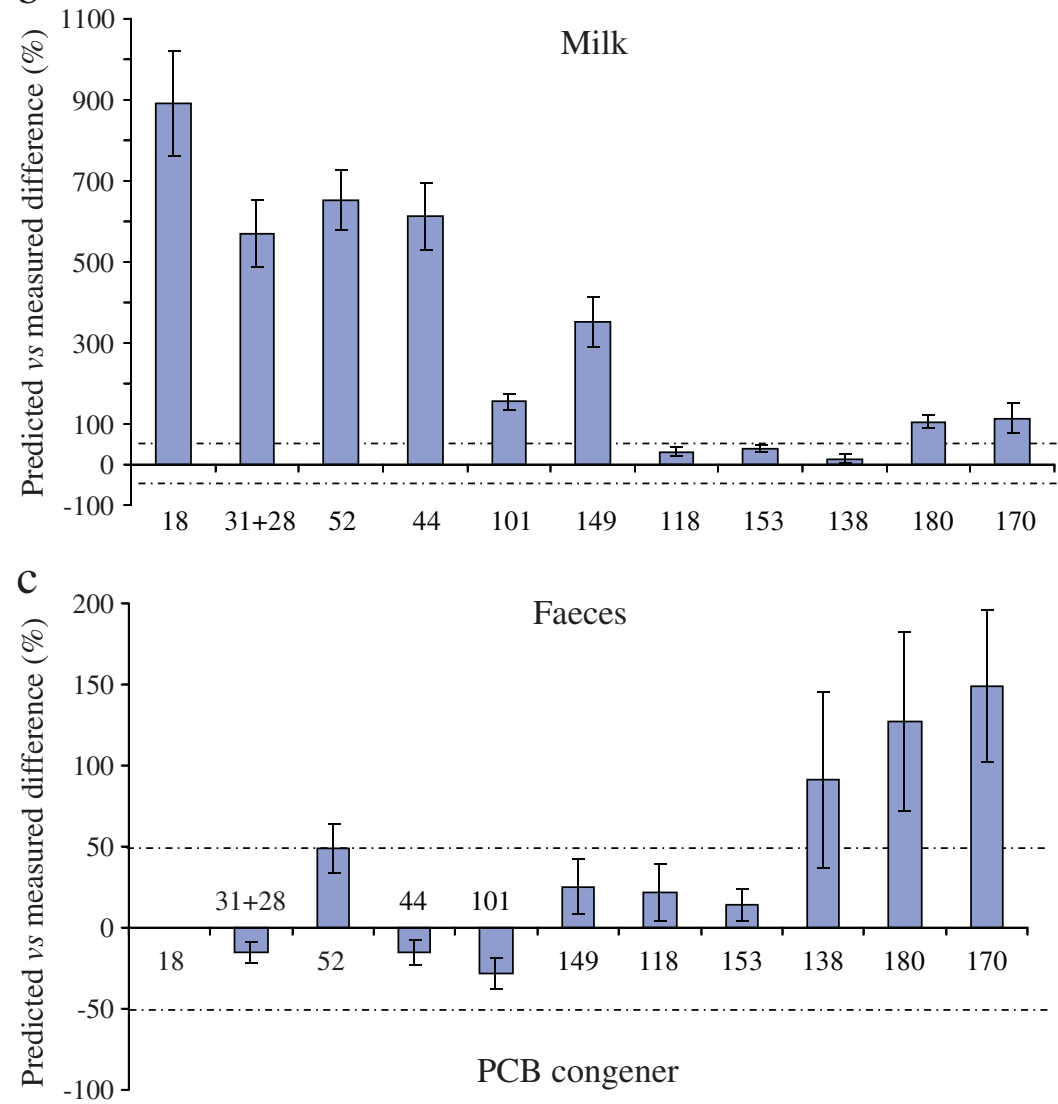

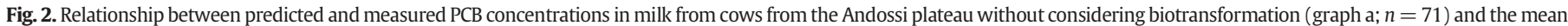

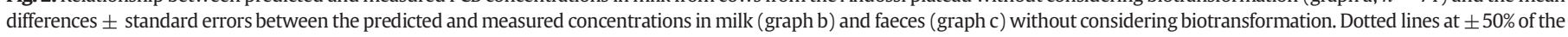

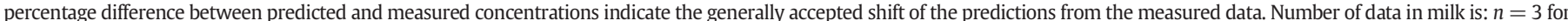

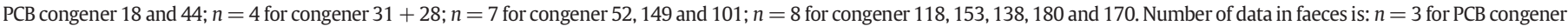
$44 ; n=4$ for congener $31+28 ; n=5$ for congener $52 ; n=6$ for congener 170 ; and $n=7$ for congener $101,149,118,153,138$ and 180 .

sporadically than vegetation because of the formers' lower relevance as contamination sources with respect to vegetation. Predicted concentrations in milk and faeces were obtained from fugacities in the blood and digestive tract, respectively. Time-resolved predicted concentrations in milk and faeces for each sampling date allow for a direct comparison between the predicted and measured concentrations in the milk (Fig. 2a), from which mean differences between predicted and measured data were derived in milk and faeces (Fig. $2 \mathrm{~b}$ and c, respectively). As expected, non-degradable congeners (e.g., CB-118 and 138) appear to be very near the 1:1 ratio, while others (e.g., CB-149, 52 and 44) that are known to be easily transformed in cows (Thomas et al., 1999b) appear to be overestimated. In Fig. $2 \mathrm{~b}$ and $\mathrm{c}$, positive percentages indicate overestimations of model predictions, while negative percentages indicate the opposite. Congeners 18, $31+28,52,44$ and 149 were predicted relatively well in the faeces ( $\pm 50 \%$ compared to measured values), while in the milk, overestimations between 3- and 9-fold were obtained. These congeners are known to be easily metabolised in cows (McLachlan, 1993; Thomas et al., 1999b) because of their substitution 
pattern (Table S5). According to the aforementioned authors and the measured faeces concentrations, biotransformation mainly happens in cow tissues through bovine metabolic pathways as opposed to the digestive tract by way of bacteria. Fig. 2c shows the model overestimations of congener 138, 180 and 170 . The following hypotheses can explain this result: a) these congeners are absorbed more easily than predicted and then efficiently accumulate in fat tissues because they are far from steady-state conditions, b) efficient degradation happens in the digestive tract via bacteria and c) overestimation of the contaminant inputs for these congeners.

Microbial biodegradation can follow different pathways depending on aerobic or anaerobic conditions, as reviewed by Abramowicz (1990, 1995) and Borja et al. (2005). In the digestive tract, aerobic biotransformation is unlikely to happen because of the anaerobic environment of the rumen and because it has not been observed for easily degradable congeners in previous PCB mass balance trials in cows (McLachlan, 1993; Thomas et al., 1999a). Although possible, anaerobic biotransformation is unlikely too because of the low substrate concentrations and the limited time available for completion. Anaerobic biodegradation was not observed in the same PCB mass balance trials (McLachlan, 1993; Thomas et al., 1999a).

Alternatively, the first hypothesis takes into account the possible differences in the absorption efficiencies under our conditions and those used in the model. For easily degradable congeners (McLachlan, 1993; Kierkegaard et al., 2009), at least, congener-specific absorption efficiencies can be calculated from measured fluxes using the following formula: absorption $(\%)=(1-$ faeces flux / input flux $) \times 100$. The absorption efficiencies observed for the easily degradable congeners in bovines during pasture $(52 \%, 58 \%, 47 \%$ and $54 \%$ for congener $31+28$, $44,52,149$, respectively) are consistent among the congeners but lower with respect to those calculated by McLachlan (in which the maximum absorption efficiency of the easily degradable congeners was $83 \%$, McLachlan, 1993) and by Thomas et al. (who calculated a maximum absorption efficiency of $82 \%$, Thomas et al., 1999b). In highaltitude pastures, spontaneous grass is digested less easily compared to silage and concentrate (Andrighetto et al., 1993), and cows have less time for digestion because they need to move to find better grazing locations. For these reasons, it can be hypothesised that PCBs are less efficiently adsorbed during pasture feeding compared to cowshed conditions. The first two hypotheses (higher absorption and biodegradation into the digestive tract), derived to explain the model overestimations observed in Fig. 2c for congeners 138, 180 and 170, must be excluded; therefore, we must accept that the observed overestimations in the faeces derive from overestimations of the PCB input fluxes of these congeners (e.g. PCB inputs from soil).

\subsection{Evaluation of new absorption parameters and biotransformation rate constants}

The lower absorption efficiencies observed in this work, in comparison to those used previously in the model (McLachlan, 1994), require the computation of new absorption transfer coefficients ( $\left.D_{\text {blood-dig }}\right)$. Following the same two-resistance approach used by McLachlan (1994) and optimising the two flux coefficients throughout the octanol-layer and the water-layer ( $Q_{0-\text { dig }}$ and $Q_{\text {water-dig }}$ in units of $\mathrm{m}^{3} \mathrm{~d}^{-1}$ ) to the mean observed fractional absorption of 0.53 , we obtained the values of $0.000242 \mathrm{~m}^{3} \mathrm{~d}^{-1}$ and $7463 \mathrm{~m}^{3} \mathrm{~d}^{-1}$ for $Q_{0 \text {-dig }}$ and $Q_{\text {water-dig, }}$ respectively (details of calculations are reported in Supplementary Information). These new parameters indicate that, in pasture conditions, the absorption efficiency of compounds that are limited by the lipid-layer resistance is lower than that predicted by the original parameters $\left(0.00058 \mathrm{~m}^{3} \mathrm{~d}^{-1}\right.$ and $4030 \mathrm{~m}^{3} \mathrm{~d}^{-1}$ for $\mathrm{Q}_{\mathrm{o}-\mathrm{dig}}$ and $\mathrm{Q}_{\text {water-dig, respective- }}$ ly). On the contrary, the absorption efficiency of compounds that are limited by the water-layer resistance is higher. The first case (lower absorption efficiency) is supported by the data of this work, while the second one derives only by the congruence of calculations (see Supplementary Information), and cannot be supported by experimental data. However, this second case is not present in our predictions because all modelled congeners have a $K_{\text {ow }}$ value lower than $2 \times 10^{7}$ and a Henry's low constant higher than 5 . Further research is necessary to confirm and better assess these parameters. The model was next evaluated using these new flux parameters, which are specific for high-altitude pasture conditions, and by introducing biotransformation rate constants for congeners that are easily metabolised in cow tissues (CB-18, $32+28$, 52,44 , and 149). First-order biotransformation rate constants were calculated by the model using the milk and faeces concentrations as the known parameters and the rate constants as the unknown variables. The model was set up for steady-state conditions; therefore, mean concentrations in milk and faeces were calculated over the whole pasture season to obtain mean contamination levels, which are suitable for approaching steady-state conditions. $D$-values for metabolism were calculated in the blood compartment ( $D_{\text {blood-met }}$ ), which has a very small lipid fraction. This model artefact produces first-order rate constants ( $k_{\text {blood-met }}$ ) that are very high (Table 2 ). This happens because excretion trough milk $\left(D_{\text {milk }}\right)$ is considered to be a continuous process that is in direct competition with the biotransformation process ( $\left.D_{\text {blood-met }}\right)$, which occurs in the blood in the model. In addition, milk has a high lipid content, while lipid level in the blood is very low (Table S2). For this reason, calculated rate constants must be considered solely as functional data to be used in the model and not actual biotransformation rate constants. More realistic data can be calculated considering the lipid volume of the whole cow instead of that which is solely in blood. In this case, we obtain much lower rate constants with much longer halflives (Table 2), but these last parameters are not suitable for use in the present version of the model. As discussed by McLachlan (1994), a more realistic version of the model should consider milk excretion as a non-continuous process that happens twice a day. Nevertheless, the functional parameters and new absorption coefficients reported above ( $Q_{\text {-dig }}$ and $Q_{\text {water-dig }}$ ) were used to again compute predicted concentrations in milk and faeces under unsteady-state conditions during the pasture season.

\subsection{Modelling elaboration optimised for high-altitude pasture conditions}

Fig. 3a shows the new relationships between the predicted and measured concentrations for each congener in milk. Linear regression $(y=1.03 \times x+0.073 ; n=71)$ gives an $R^{2}$ value of 0.81 , much higher than the value that was previously obtained (Fig. $2 \mathrm{a} ; y=0.96 \times$ $\left.x+0.32 ; n=71 ; R^{2}=0.62\right)$. Mean differences between predicted and measured concentrations are below $\pm 50 \%$ in both milk

Table 2

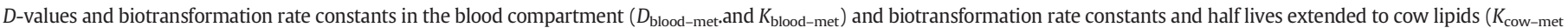
and half life).

\begin{tabular}{|c|c|c|c|c|c|}
\hline PCB congener & Substitution pattern & $D_{\text {blood-met }} \mathrm{mol} \mathrm{d}^{-1} \mathrm{~Pa}^{-1}$ & $K_{\text {blood-met }} \mathrm{d}^{-1}$ & $K_{\text {cow-met }} \mathrm{d}^{-1}$ & Half life d \\
\hline 18 & $2,2^{\prime}, 5$-tri-CB & 26.5 & 200 & 0.039 & 18 \\
\hline $31+28$ & $2,4^{\prime}, 5$-tri-CB $+2,4,4^{\prime}$-tri-CB & 74.0 & 182 & 0.036 & 20 \\
\hline 44 & $2,2^{\prime}, 3,3^{\prime}$-tetra-CB & 144 & 167 & 0.033 & 21 \\
\hline 52 & $2,2^{\prime}, 5,5^{\prime}$-tetra-CB & 107 & 181 & 0.035 & 20 \\
\hline 149 & $2,2^{\prime}, 3,4^{\prime}, 5^{\prime}, 6$-hexa-CB & 420 & 87.7 & 0.017 & 41 \\
\hline
\end{tabular}




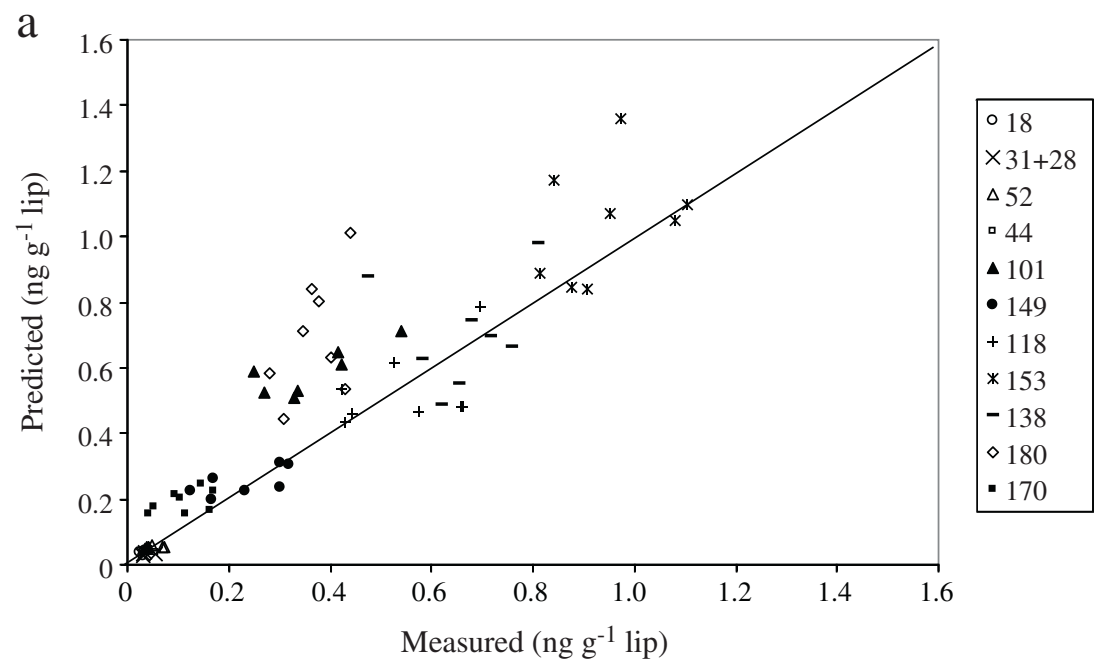

b
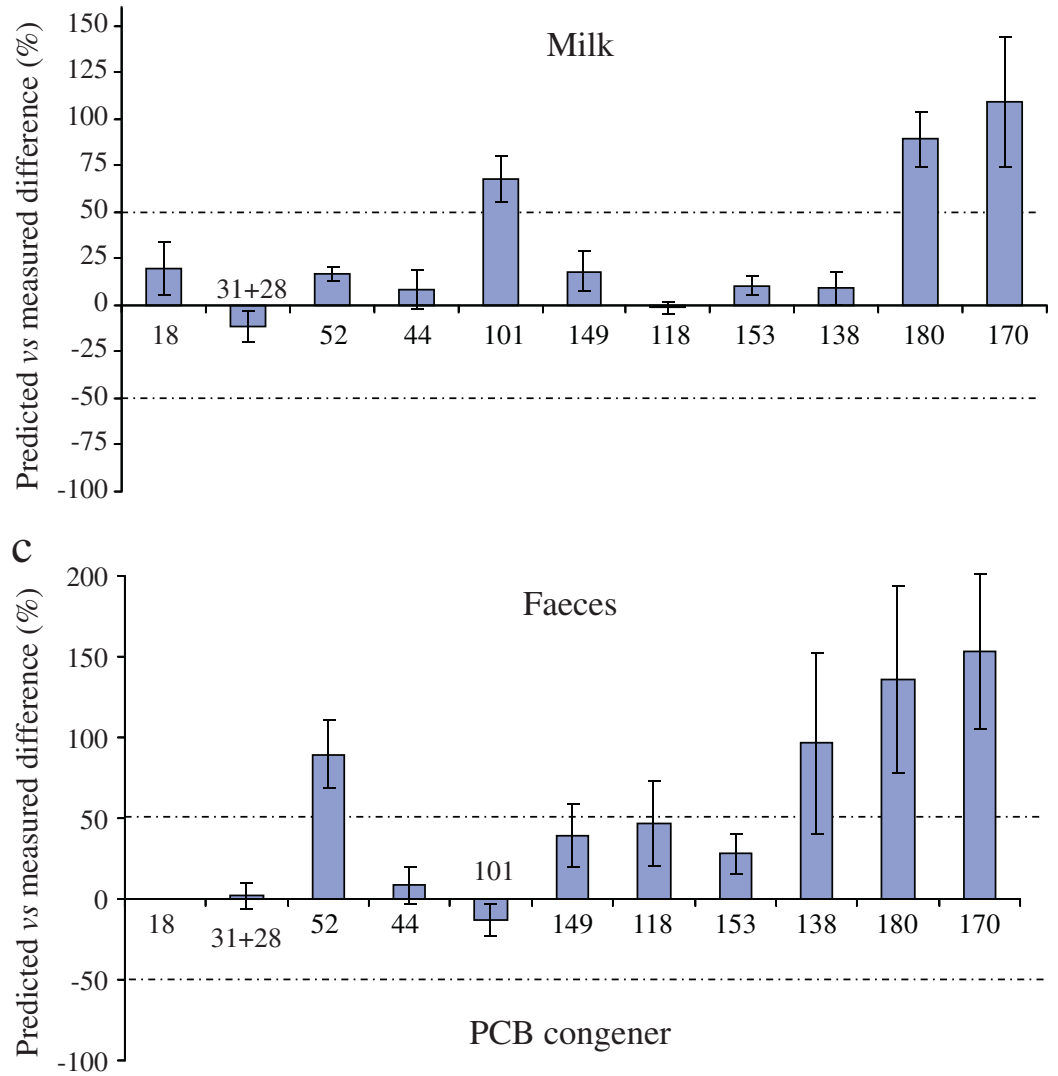

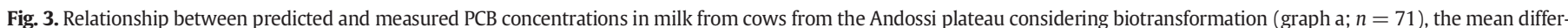

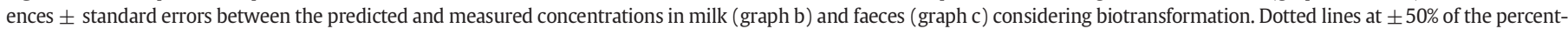

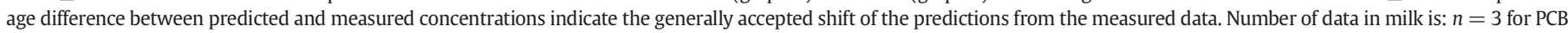

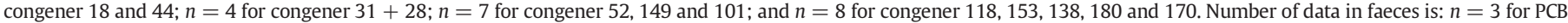
congener $44 ; n=4$ for congener $31+28 ; n=5$ for congener $52 ; n=6$ for congener $170 ; n=7$ for congener $101,149,118,153,138$ and 180 .

and faeces for most of the considered congeners (Fig. 3b and c) and are within $\pm 20 \%$ for some. Only CB-170 and CB-180 were overestimated in both faeces and milk (Fig. $3 \mathrm{~b}$ and $\mathrm{C}$ ). These congeners are known to be highly resistant to degradation both in the cow and in the environment; therefore, their low concentrations in both these matrices are difficult to explain. The great distance from steady-state conditions that could justify these low concentrations in milk seems to be unsupported by the data. Dairy cows are usually kept in near constant conditions (same feeding) for long periods of time during their milking life (generally 6 years). The milk sample taken before pasture (T1), when the cows are kept under cowshed conditions at low altitude, suggests that the same bovines have been exposed to a similar or even higher contamination intake in wintertime. In fact, the PCB concentration in the milk before pasture (5.91 ng $\Sigma$ PCBs $\mathrm{g}^{-1}$ lip) was higher than the mean milk contamination determined 
Table 3

Time to reach $90 \%\left(T_{90}\right)$ and 95\% ( $\left.T_{95}\right)$ of steady-state condition and clearance half-time for the considered congeners.

\begin{tabular}{|c|c|c|c|}
\hline PCB congener & $\begin{array}{l}T_{90} \\
d\end{array}$ & $\begin{array}{l}T_{95} \\
d\end{array}$ & $\begin{array}{l}\text { Half-time } \\
\text { d }\end{array}$ \\
\hline 18 & 87 & 117 & 33 \\
\hline $28+31$ & 95 & 130 & 36 \\
\hline 52 & 100 & 138 & 38 \\
\hline 44 & 97 & 133 & 37 \\
\hline 101 & 210 & 315 & 140 \\
\hline 149 & 187 & 254 & 70 \\
\hline 118 & 270 & 400 & 150 \\
\hline 153 & 330 & 470 & 160 \\
\hline 138 & 500 & 690 & 205 \\
\hline 180 & 465 & 650 & 195 \\
\hline 170 & 540 & 740 & 215 \\
\hline 194 & 1215 & 1600 & 410 \\
\hline 209 & 2800 & 3660 & 880 \\
\hline
\end{tabular}

under pasture conditions ( $3.25 \pm 0.62 \mathrm{ng} \Sigma \mathrm{PCBs} \mathrm{g}^{-1} \mathrm{lip}$ ). An overestimation of the PCBs input for these two congeners is the most probable explication. Specific data obtained under highly controlled conditions are necessary to support this speculation. On the contrary, the present research was mainly focused on low-controlled pasture conditions; therefore, no further discussion is proposed.

By the model, times needed to reach steady-state conditions (90\% and 95\%) and clearance half-life can be calculated for the congeners analysed (Table 3 ). In the literature accumulation and depuration kinetics of PCBs were studied in both milk fat (Rossi et al., 2010) and body fat (Fries et al., 1973; Fries, 1977; McLachlan, 1994). Kinetics in milk fat are much faster because of the fast transfer between feed and milk (Fries, 1977). Rossi et al. (2010), in a depuration study (cows from high to low contamination diet) reported consistent reduction of CB-18 and 52 in milk during the first week, and a reduction of the PCB sum in milk of one order of magnitude in 144-200 days). 30-70 and 100-200 days are the modelled half life for labile and persistent congeners, respectively (Table 3). Data of Table 3 refer to the whole-cow budget, substantially to the cow fat, and therefore accumulation and depuration are much slower than that calculated for milk. Kinetics studies on the body fat were reported by Fries et al. (1973) and by McLachlan (1994). Accumulation data of Aroclor 1254 in fat show that, within the 60 days of the trial, near equilibrium in fat wasn't achieved and depuration half lives was longer than this interval. Data of Ewers reported by McLachlan (1994) showed clearance half life longer than 10 weeks for CB-138. Direct comparisons are difficult but

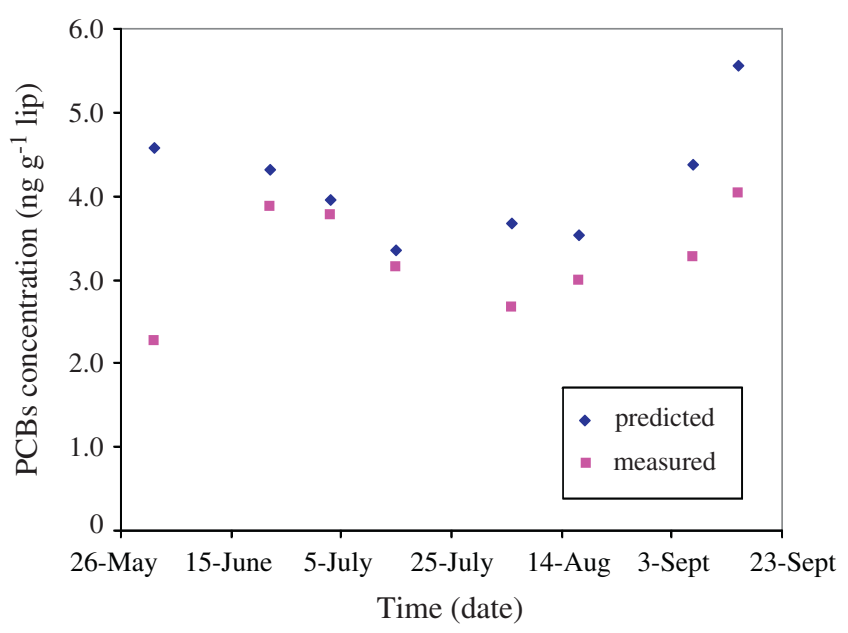

Fig. 4. Seasonal trend of measured and predicted concentrations of the $\Sigma \mathrm{PCBs}$ in milk from cows from the Andossi plateau $(n=8)$. experimental data seems to generally accord to those reported in Table 3.

Because the main contamination source (grass vegetation) was characterised by a complex seasonal trend (Fig. S4), it is interesting to analyse the same trend in milk. Predicted and measured concentrations of $\Sigma$ PCBs during the 2011 pasture season are shown in Fig. 4. Both the predicted and measured concentrations seem to qualitatively draw the same seasonal trend characterised by lower concentrations in the middle of the pasture season (July and August) and higher levels at the end of the pasture season (September). In the middle of summer, when temperatures are high, the concentrations in the vegetation and in milk appear to be at the lower levels, while in September, when temperatures become low, PCB concentrations in the vegetation reach higher levels than before (July and August) and also concentrations in milk seem to rise, drawing a seasonal trend opposite to that of temperature. The effect of temperature on the accumulation in plants was reviewed by Barber et al. (2004). The only inconsistent result was the first measured datum in the milk, which was the lowest measured concentration in milk (2.24 $\mathrm{ng} \Sigma$ PCBs $\mathrm{g}^{-1}$ lip), in a period when the concentrations in the vegetation were still high. The possibility that it might derive from a period (before pasture) of lower contamination input should be excluded because milk contamination before pasture (T1) was even higher.

\section{Conclusions}

The application of McLachlan's model to the pasture conditions analysed herein highlights, once more, the importance of the biotransformation processes in vegetation-to-milk PCB transfer. To our knowledge, PCB biotransformation in dairy cows has mainly been evaluated semi-quantitatively, for example, following the approach of Thomas et al. (1999b), in which the relative ratios between concentrations in the milk and in the gastro-intestinal tract are both normalised using congener 153 . In the present work, the calculated half-lives, extrapolated to the whole cow, ranged between 18 and $41 \mathrm{~d}$ for congeners 18 and 149, respectively. Further investigations might evaluate how much these values depend on the cow species or breeding modalities. Maximal absorption efficiency find in this research (53\%) highlights that PCB contamination in milk can be lower in high-mountain pasture conditions than in cowshed conditions, where PCB absorption efficiencies appear to be higher. Unfortunately, we do not have sufficiently reliable data to more extensively evaluate the relationship between absorption efficiency and the $K_{\mathrm{ow}}$ values of different congeners (especially highly chlorinated ones). Modelled and measured data in milk highlight the importance of the seasonal trend of the contamination. 


\section{Acknowledgement}

The authors are very grateful to Mr. Donnino Della Bella and 'Consorzio Alpe Andossi' for their hospitality and for providing samples and useful information. We are also very grateful to the reviewers for providing an accurate revision of the paper and for their very useful suggestions.

\section{Appendix A. Supplementary data}

Supplementary data to this article can be found online at http://dx. doi.org/10.1016/j.scitotenv.2014.04.042.

\section{References}

Abramowicz DA. Aerobic and anaerobic biodegradation of PCBs: a review. Crit Rev Biotechnol 1990;10:241-51.

Abramowicz DA. Aerobic and anaerobic PCB biodegradation in the environment. Environ Health Perspect 1995;103:97-9.

Andrighetto I, Cozzi G, Berzaghi P, Zancan M. Avoidance of degradation of Alpine pasture through grazing management: investigation of change in vegetation nutrition characteristics as a consequence of sheep grazing at different periods of the growing season. Land Degrad Rehabil 1993;4:37-43.

Barber JL, Thomas GO, Kerstiens G, Jones KC. Current issues and uncertainties in the measurement and modelling of air-vegetation exchange and within-plant processing of POPs. Environ Pollut 2004;128:99-138.

Böhme F, Welsch-Pausch K, McLachlan MS. Uptake of airborne semivolatile organic compounds in agricultural plants: field measurements of interspecies variability. Environ Sci Technol 1999;33:1805-13.

Borja J, Taleon DM, Auresenia J, Gallardo S. Polychlorinated biphenyls and their biodegradation. Process Biochem 2005;40:1999-2013.

Bovolenta S, Saccà E, Ventura W, Piasentier E. Effect of type and level of supplement on performance of dairy cows grazing on Alpine pasture. Ital J Anim Sci 2002;1:255-63.

Breivik K, Sweetman A, Pacyna JM, Jones KC. Towards a global historical emission inventory for selected PCB congeners-a mass balance approach. 1.Global production and consumption. Sci Total Environ 2002;290:181-98.

Costera A, Feidt C, Marchand P, Le Bizec B, Rychen G. PCDD/F and PCB transfer to milk in goats exposed to a long-term intake of contaminated hay. Chemosphere 2006;64: 650-7.

Daly GL, Lei YD, Teixeira C, Muir DCG, Castillo LE, Wania F. Accumulation of current-use pesticides in neotropical montane forests. Environ Sci Technol 2007:41:1118-23.

Derks HJGM, Berende PLM, Olling M, Everts H, Liem AKD, de Jong APJM. Pharmacokinetic modelling of polychlorinated dibenzo-p-dioxins (PCDDs) and furans (PCDFs) in cows. Chemosphere 1994;28:711-5.

Duàrte-Davidson R, Jones KC. Polychlorinated biphenyls (PCBs) in UK population: estimated intake, exposure and body burden. Sci Total Environ 1994;151:131-52.

Esposito M, Cavallo S, Serpe FP, D'Ambrosio R, Gallo P, Colarusso G, et al. Levels and congener profiles of polychlorinated dibenzo-p-dioxins, polychlorinated dibenzofurans and dioxin-like polychlorinated biphenyls in cow's milk collected in Campania, Italy. Chemosphere 2009;77:1212-6.

Focant JF, Pirard C, Massard AC, de Pauw E. Survey of commercial pasteurised cow's milk in Wallonia (Belgium) for the occurrence of polychlorinated dibenzo-p-dioxins, dibenzofurans and coplanar polychlorinated biphenyls. Chemosphere 2003;52:725-33.

Fries GF. The kinetics of halogenated hydrocarbon retention and elimination in dairy cattle. In: Ivie GW, Dorough HH, editors. Fate of pesticides in the large animal. New York: Academic Press; 1977. p. 159-73.

Fries GF. Ingestion of sludge applied organic chemicals by animals. Sci Total Environ 1996; 185:93-108.

Fries GF, Marrow GS, Gordon CH. Long-term studies of residue retention and excretion by cows fed a polychlorinated biphenyl (Aroclor 1254). J Agric Food Chem 1973;21:117-21.

Fries GF, Marrow GS, Snow PA. Soil ingestion by dairy cattle. J Dairy Sci 1982;65:611-8.

Gibb MJ, Ivingst WE, Dhanoa MS, Sutton JD. Changes in body components of autumncalving Holstein-Friesian cows over the first 29 weeks of lactation. Anim Prod 1992; 55:339-60.
Gobas FAPC, Zhang X. Wells R. Gastrointestinal magnification: the mechanism of biomagnification and food chain accumulation of organic chemicals. Environ Sci Technol 1993;27:2855-63.

Guazzoni N, Comolli R, Mariani L, Cola G, Parolini M, Binelli A, et al. Meteorological and pedological influence on the PCBs distribution in mountain soils. Chemosphere 2011;83:186-92.

Kierkegaard A, De Wit CA, Asplund L, McLachlan MS, Thomas GO, Sweetman AJ, et al. A mass balance of tri-hexabrominated diphenyl ethers in lactating cows. Environ Sci Technol 2009;43:2602-7.

Luzardo OP, Almeida-González M, Henríquez-Hernández LA, Zumbado M, Álvarez-León, Boada LD. Polychlorobiphenyls and organochlorine pesticides in conventional and organic brands of milk: occurrence and dietary intake in the population of the Canary Islands (Spain). Chemosphere 2012;88:307-15.

Mackay D. Multimedia environmental model, the fugacity model. 2nd ed. Boca Raton, Florida: Lewis Publisher; 2001.

Mamontova EA, Tarasova EN, Momontov AA, Kusmin MI, McLachlan MS, Khomutova MI. The influence of soil contamination on the concentrations of PCBs in milk in Siberia. Chemosphere 2007;67:571-8.

Matthews HB, Dedrick RL. Pharmacokinetics of PCBs. Annu Rev Pharmacol Toxicol 1984; 24:85-103.

McLachlan MS. Mass balance of polychlorinated biphenyls and other organochlorine compounds in a lactating cow. J Agric Food Chem 1993:41:474-80.

McLachlan MS. Framework model of the fate of hydrophobic contaminants in cows. Environ Sci Technol 1994;28:2407-14.

McLachlan MS. A simple model to predict accumulation of PCDD/Fs in an agricultural food chain. Chemosphere 1997;34:1263-76.

McLachlan MS, Thoma H, Reissinger M, Hutzinger O. PCDD/F in an agricultural food chainpart 1: PCDD/F mass balance in a lactating cow. Chemosphere 1990;20:1013-20.

Nizzetto L, Pastore C, Liu X, Camporini P, Stroppiana D, Herbert B, et al. Accumulation parameters and seasonal trends for PCBs in temperate and boreal forest plant species. Environ Sci Technol 2008;42:5911-6.

Olling M, Derks HJGM, Berende PLM, Liem AKD, de Jong APJM. Toxicokinetics of eight ${ }^{13} \mathrm{C}-$ labelled polychlorinated dibenzo-p-dioxins and furans in lactating cows. Chemosphere 1991;23:1377-85.

Petro EML, Covaci A, Leroy JLMR, Dirtu AC, De Coen W, Bols PEJ. Occurrence of endocrine disrupting compounds in tissues and body fluids of Belgian dairy cows and its implications for the use of the cow as a model to study endocrine disruption. Sci Total Environ 2010;408:5423-8.

$\mathrm{R}$ Core Team. R: a language and environment for statistical computing. Vienna, Austria: R Foundation for Statistical Computing 3-900051-07-0; 2013 [URL http://www.R-project.org/]

Rossi F, Bertuzzi T, Vitali A, Rubini A, Masoero F, Morlacchini M, et al. Monitoring of the declining trend of polychlorobiphenyls concentration in milk of contaminated dairy cows. Ital J Anim Sci 2010;9:88-92.

Rychen G, Jurjanz S, Toussaint H, Feidt C. Dairy ruminant exposure to persistent organic pollutants and excretion to milk. Animal 2008;2:312-23.

Slob W, Olling M, Derks HJGM, de Jong APJM. Congener specific bioavailability of PCDD/Fs and coplanar PCBs in cows: laboratory and field measurements. Chemosphere 1995; 31:3827-38.

Sweetman AJ, Thomas GO, Jones KC. Modelling the fate and the behaviour of lipophilic organic contaminants in lactating dairy cows. Environ Pollut 1999;104:261-70.

Tato L, Tremolada P, Ballabio C, Guazzoni N, Parolini M, Caccianiga M, et al. Seasonal and spatial variability of polychlorinated biphenyls (PCBs) in vegetation and cow milk from a high altitude pasture in the Italian Alps. Environ Pollut 2011;159:2656-64.

Thomas GO, Sweetman AJ, Jones KC. Input-output balance of polychlorinated biphenyls in a long term study of lactating daily cow. Environ Sci Technol 1999a;33:104-12.

Thomas GO, Sweetman AJ, Jones KC. Metabolism and body-burden of PCBs in lactating dairy cows. Chemosphere 1999b;39:1533-44.

Tremolada P, Villa S, Bazzarin P, Bizotto E, Comolli R, Vighi M. POPs in mountain soils from the Alps and Andes: suggestions for a 'precipitation effect' on altitudinal gradients. Water Air Soil Pollut 2008;188:93-109.

Wania F, Su Y. Quantifying the global fractionation of polychlorinated biphenyls. Ambio 2004;33:161-8. 